\title{
Isotropic finishing of austempered iron casting cylindrical parts by roller burnishing
}

\author{
A. Rodriguez $^{1} \cdot$ L. N. López de Lacalle ${ }^{1} \cdot$ O. Pereira $^{1} \cdot$ A. Fernandez $^{1} \cdot$ I. Ayesta $^{1}$ \\ Received: 14 May 2020 / Accepted: 9 August 2020 / Published online: 16 August 2020 \\ (C) Springer-Verlag London Ltd., part of Springer Nature 2020
}

\begin{abstract}
Roller burnishing technique to achieve isotropic surface topography on cylindrical components made of austempered ductile iron (ADI) casting is presented in this paper. In the last years, ADI casting components are used in many mechanical applications, due to their enhanced mechanical properties. ADI castings are difficult-to-cut materials; therefore, advanced techniques to improve manufacturing productivity are necessary and under research. On the other hand, spiral roughness pattern produced by turning operation is a common source of unconformities in several applications. Turning produces a defined kinematic pattern, similar to a thread. This work presents a theoretical and experimental validation using different burnishing conditions. Roughness and surface topography and surface integrity were checked. Results show that the technique greatly improves surface roughness, and eliminates the kinematic-driven roughness pattern of turning, leading to a more isotropic finishing. A comparison between roller burnishing and ball burnishing is also presented in this paper.
\end{abstract}

Keywords Roller burnishing, $\cdot$ Austempered ductile iron, $\cdot$ ADI isotropic finishing, $\cdot$ Surface integrity, $\cdot$ Topography

\section{Introduction}

The combination of novel materials and advanced manufacturing processes is key in many manufacturing sectors such as aeronautics, automotive, gear industry, heavy duty equipment, etc. In this work, the use of a novel cross-hatch type technique using conventional roller burnishing tools applied on austempered ductile iron (ADI) casting components is presented. Some relevant research results were presented by authors previously in [1] about burnishing of rotary components. Moreover, the elimination of surface profile generated after turning brake disks was also analyzed by authors

\section{Highlights}

- A novel procedure to get surface topography with cross-hatch patterns is presented using the roller burnishing technique.

- A proposed finishing operation is developed for ADI materials.

- Burnishing parameters and their influence are analyzed for cylindrical components.

- Isotropic and no-directional pattern is obtained after turning

L. N. López de Lacalle norberto.lzlacalle@ehu.eus

1 Aeronautics Advanced Manufacturing Center (CFAA), University of the Basque Country (UPV/EHU), Parque Tecnológico de Zamudio 202, 48170 Bilbao, Spain applying abrasive brushes [2]. Turning operation always induces a kinematically defined pattern, with spirals on part surfaces or thread-like profiles. Spiral/thread patterns can bring up many problems, such as leakage of oil in sealed zones in gearboxes, vibrations in brakes, and many others. In some applications, manufacturing requirements forbid turning due to this drawback.

In the field of cast iron materials, gray cast iron, in which graphite is in form of layers, was replaced years ago in some applications by ductile cast iron, also known as nodular cast iron or spheroidal graphite cast iron. This one, developed and patented around 1948, is formed by graphite spheroids in a metal matrix, giving superior mechanical characteristics [3]. This material was quickly introduced in equipment designs to make lightweight components [4]. Afterward, ADI (austempered ductile iron) castings represented a new step in the evolution. In ADI, graphite still appears spheroidal, but the rest of the microstructure forms the so-called austoferrite. Thus, ADI casting 5-stage heat treatment (heating, austenitizing, quenching, austempering, and final cooling) causes that acicular ferrite retains the carbon-stabilized austenite, named ausferrite microstructure. Austempering temperature determines the structure quality and final mechanical properties. Austempered Ductil Iron (ADI) began to be used in the 1980s, spread in the automotive sector for components 
of high-end vehicles; since then, the increase was spectacular. This is because parts made of this material show an excellent strength-to-weight ratio, improving significantly ratio values offered by aluminum alloys, steel, and other castings [5, 6]. ADI mechanical properties are superior to pearlite ductile castings and forged steels, which has a maximum strength of around $700 \mathrm{MPa}$. In ADI, ultimate strength ranges from 800 to $1400 \mathrm{MPa}$, being those between 800 and 1100 the most used because they keep good ductility. For instance, ADI 1000 is a logical step from ductile iron grade around $700 \mathrm{MPa}$. Standards for ADI are ISO 17804-2005, EN1564, and ASTM A897M [7]; see table and Fig. 1. Hence, ADI 900 is achieved at temperatures of $390^{\circ}$, while the hardest and most strength ones at lower temperatures.

Regarding machining [8, 9], the first choice for ADI removal is the use of carbide inserts type $\mathrm{K}$, as is recommended for the rest of castings. However, ADI castings have lower machinability than other castings, resulting in increased tool wear due to abrasion and adhesion phenomena.

In order to reduce machining time, burnishing techniques could eliminate finishing turning operations. The idea is to maintain roughing operation conditions, applying burnishing just afterward. The sequence allows to achieve the final surface roughness, reducing both time and costs. Moreover, combining turning and burnishing in opposite directions (i.e., turning is clockwise, and the other is counterclockwise), it would be possible to eliminate the directional roughness pattern, typical of turning parts. Another fact to take into account is that residual stresses are also critical [10] in many applications; burnishing process introduces compressive residual stresses and strain hardening on workpiece surfaces, which are excellent for improving fatigue life.

Burnishing is a simple operation, inexpensive and which generates high-quality final surfaces [11-13]. The type roller burnishing technology (known as rolling) is applied in lathes, and it allows finished surfaces within the quality of grinding (i.e., less than 1- $\mu \mathrm{m} \mathrm{Ra}$ ). Thus, roller burnishing can replace finishing processes and mechanical treatments such as grinding, shot peening, or hand polishing. In addition, burnishing is applied on the same machines' tools than the previous turning, using inexpensive additional burnishing tools. Burnishing is based on making small plastic deformations generating a material displacement that modifies surface topography microirregularities. This mechanism is performed by a rolling element that moves onto the just machined surface, applying a regular compression force at the same time.

Burnishing systems can be (a) roller-type, in this case the process is known as "rolling" or "roller burnishing" and (b) ball-type $[14,15]$ whereby the term "ball burnishing" is used. Otherwise, deep ball burnishing commonly refers to a hydrostatic burnishing tool capable of supplying pressures of 20 $30 \mathrm{MPa}$, introducing compressive residual stresses over $1 \mathrm{~mm}$ in depth. A variation of this technique is the so-called lowplasticity burnishing (LPB) by Golden and Shepard [16]. LPB is a mechanical surface enhancement technology developed and patented at Lambda Technologies ${ }^{\circledR}$. This technique uses a minimal amount of plastic deformation needed to create the desired level of compressive stress. LPB is mainly applied to improve the fatigue properties of gas turbine engine components [17]. Burnishing was also used combined with other
Fig. 1 Heat treatment for austempering, ADI grades, and austoferrite structure. High strength ADI grades are achieved at lower austempering temperatures. The picture is of ADI 1000, showing austoferrite

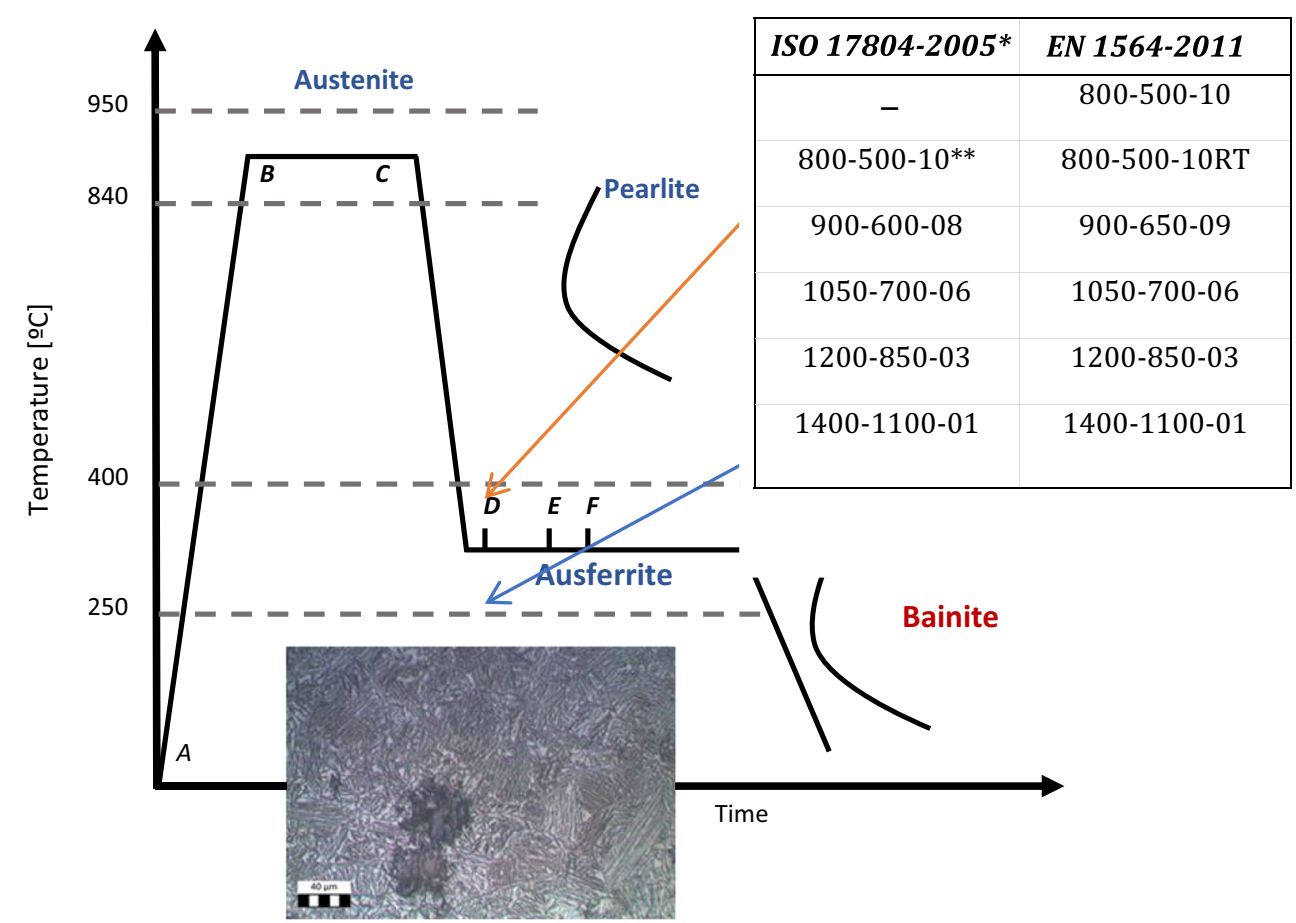



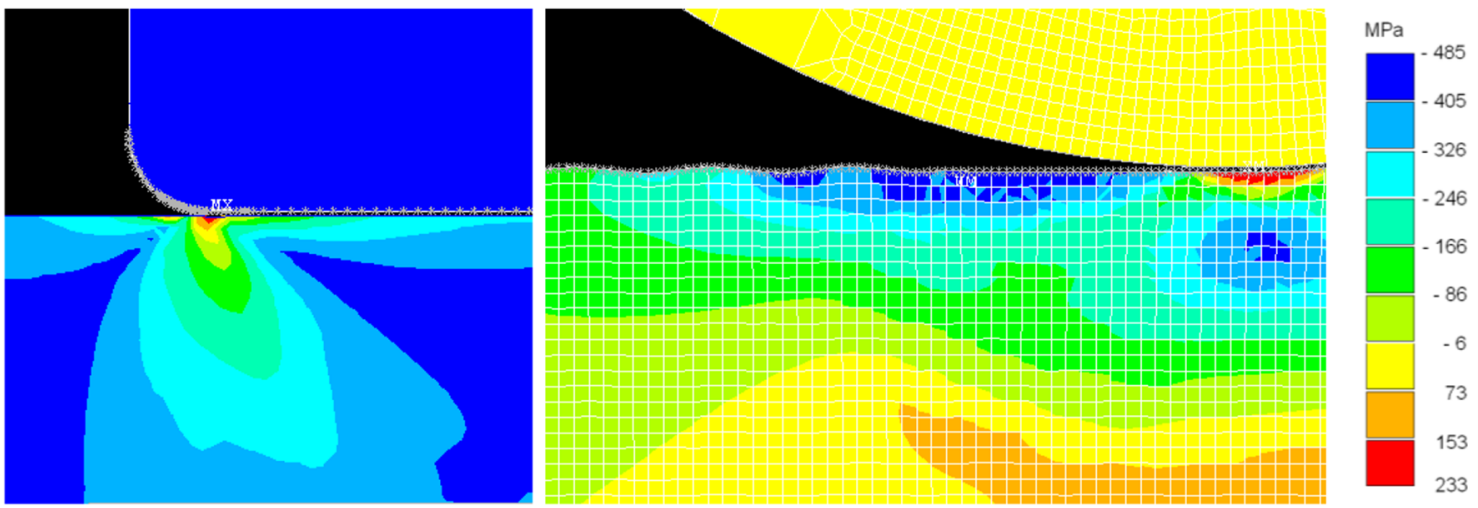

Fig. 2 Geometry of the multi-pass 2D model for roller burnishing process. Stress field obtained during contact and after simulation

industrial manufacturing processes, such as friction stir welding [18, 19] or incremental sheet forming [20]. Burnishing improves the surface quality [12]; increases the surface hardness of the workpiece [21]; produces high compressive residual stresses in the workpiece surface [22]; and, as a result, increases corrosion resistance, wear resistance, and fatigue life, as presented by authors in [23, 24]. Thus, burnishing can replace other finishing processes, such as grinding, shot peening [25], or hand polishing.

During the last decades, several predictive models were developed for the burnishing process and, consequently, to analyze the influence of process parameters in the workpiece surface properties. Models of burnishing are classified in three categories, (a) statistical, (b) analytical, and (c) FEM models. Thus, some authors [26] developed statistical models based on the response surface method (RSM) to relate surface roughness to burnishing parameters, but these do not represent physical phenomena occurring during the process. Other works $[27,28]$ presented analytical models to determine roughness of burnished surfaces. The equations presented depend on rolling or

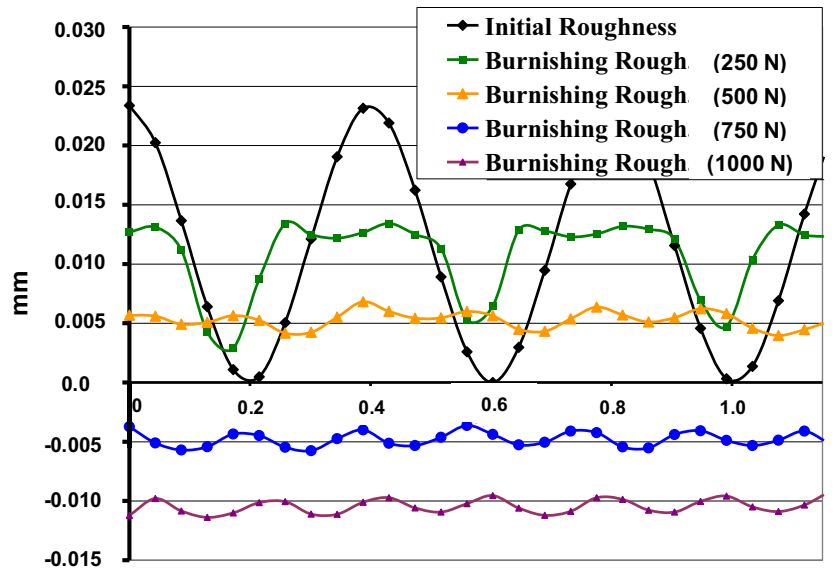

$\mathrm{mm}$

Fig. 3 Effect of burnishing force on surface profile, rolling feed $f b=$ $0.2 \mathrm{~mm} / \mathrm{rev}$ burnishing feed, on the normal displacement of the ball, and on the initial surface roughness from previous turning and/or grinding. Finally, some authors developed FEM models, capable of predicting surface integrity [29, 30]; in this work, a novel FEM model is also presented in order to understand the rolling process through a theoretical approach. Tajane and Pawar [31] considered burnishing as an alternative to heat treatment and grinding operations, which results into minimization of cycle time. On the other hand, Travieso et al. [32] applied burnishing to workpieces with a convex or concave surface.

Grinding operation is also concerned by surface state [33-35]. Burnishing and rolling can compete with grinding regarding the final surface finishing; besides, grinding does not introduce a defined pattern on roughness, whereas machining processes introduced it [2]. That is why some brake disks are ground after turning. Grinding implies near-toisotropic roughness, but machine-tool and process are more expensive.

The present work proposed an easy way to achieve isotropic finishing in pieces by means of rolling or burnishing.

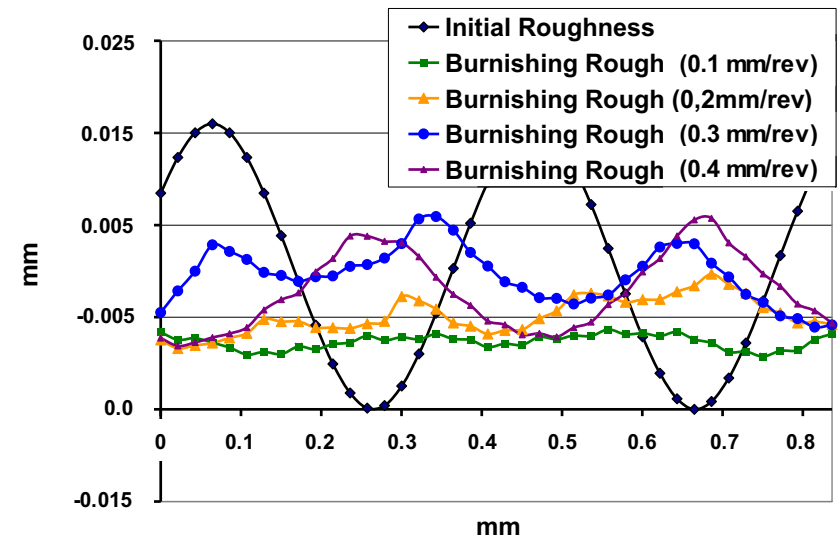

Fig. 4 Roughness profiles obtained with different burnishing feed, force $=500 \mathrm{~N}$ 


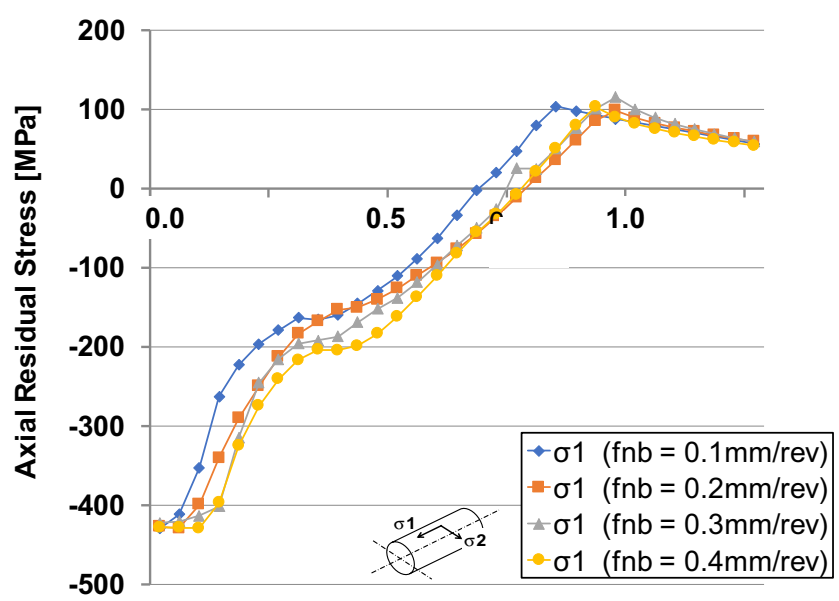

Fig. 5 Prediction of the residual stresses (in the axial direction) for different burnishing feed rates, along depth

\section{Isotropic and surface integrity: A numerical approach}

Burnishing is a cold-working process performed on a previously machined surface; in many cases, burnishing is applied immediately after turning or milling. So the process is based on making small plastic deformations on part surfaces, which causes material displacement from the "peaks or ridges" to the "valleys or depressions" of surface micro-irregularities. This mechanism is performed by a rolling element (the tool, it can be a ball or a roller) that moves on the surface, applying a regular compression force.

The "crushing" causes four effects on the surface:

1. Reduction of surface roughness in more than an order of magnitude. The final quality is similar to grinding, even reaching a mirror-like aspect.

2. Generation of high compression residual stresses on workpiece surfaces, which is beneficial for the component fatigue behavior. Moreover, the absence of heat produced by this mechanical surface treatment prevents from metallurgical changes on surfaces.

3. Surface hardness increment, between 30 and $60 \%$ (HBN) in mild steel and cast iron cases.

Table 1 Parameter definitions for ADI 1000 testing experiments

\begin{tabular}{lllll}
\hline & & Test 1 & Test 2 & Test 3 \\
\hline \multirow{3}{*}{ Turning } & $V_{\mathrm{c}}[\mathrm{m} / \mathrm{min}]$ & 80 & 80 & 80 \\
& $f_{\mathrm{n}}[\mathrm{mm} / \mathrm{rev}]$ & 0.4 & 0.4 & 0.4 \\
\multirow{4}{*}{ Burnishing } & $F_{\mathrm{b}}[\mathrm{N}]$ & 1000 & 1000 & 1000 \\
& $f_{\mathrm{nb}}[\mathrm{mm} / \mathrm{rev}]$ & 0.4 & 0.2 & 0.1 \\
& $V_{\mathrm{b}}[\mathrm{m} / \mathrm{min}]$ & 80 & 100 & 120 \\
\hline
\end{tabular}

4. Dimensions are within tight tolerances $(<0.01 \mathrm{~mm})$. In fact, using special tools for hole calibration is a typical application of spring-type burnishing devices, mandrel type.

The state of the art of numerical models for mechanical surface treatments is still on a fundamental level. Finite element method (FEM) models are available in academics and research projects, due to their potential, for an early prediction of the effects induced for these processes, and the possibility to reduce physical testing. This section aims to present a FEM model for burnishing, which allows the study of the influence of parameters such as burnishing feed and pressure on workpiece surface roughness and residual stresses.

Burnishing is a three-dimensional process; however, the use of a 3D FEM model supposes significant computational times, and it does not give better results than simplified 2D models. A 2D model is easier to propose and permits to study the process parameters' influence on surface finish level and residual stresses. In this study, workpiece material was steel of ultimate strength $1000 \mathrm{MPa}$, because data for ADI 1000 are not in literature. The 2D FEM model process parameters were (i) initial turning roughness, (ii) burnishing pressure, and (iii) feed of the burnishing tool (similar in concept to the turning feed, so it is measured $(f b)$ in $\mathrm{mm} / \mathrm{rev}$ ).

A multiple-pass indentation process was considered, as shown in Fig. 2. The full formulation, which includes large strain elastoplastic and contact models, is defined in a previous authors' work [1]. Hence, plane strain conditions were assumed with displacement constraints located very far from the burnishing zone to avoid edge effects. The domain was discretized with four-noded isoparametric finite elements with standard Gauss integration quadrature and a B-bar technique to circumvent the plastic volumetric locking. The meshing in the region where the indenter acts needs to be fine enough in order to improve the accuracy of the results in this region, a zone in which large gradients in the solution variables are expected. A mesh refinement sensitive analysis was previously carried out in order to ensure mesh-independent results. Thus, the resulting element size in the indentation region was $5 \times 5 \mu \mathrm{m}$. The rolling tool was considered as a perfectly rigid body (rolling tools are made in ceramic or carbides, very stiff).

\subsection{Surface characteristics}

One of the more relevant outputs is surface roughness. It is really interesting to know how the profile will be just using numerical modeling. Some simulations were carried out and surface profile was obtained for each one. To calculate the profile, several nodes of the previous turned profile were selected and $\mathrm{Y}$ axis displacements were calculated. In this way, each simulated profile was obtained through the difference 

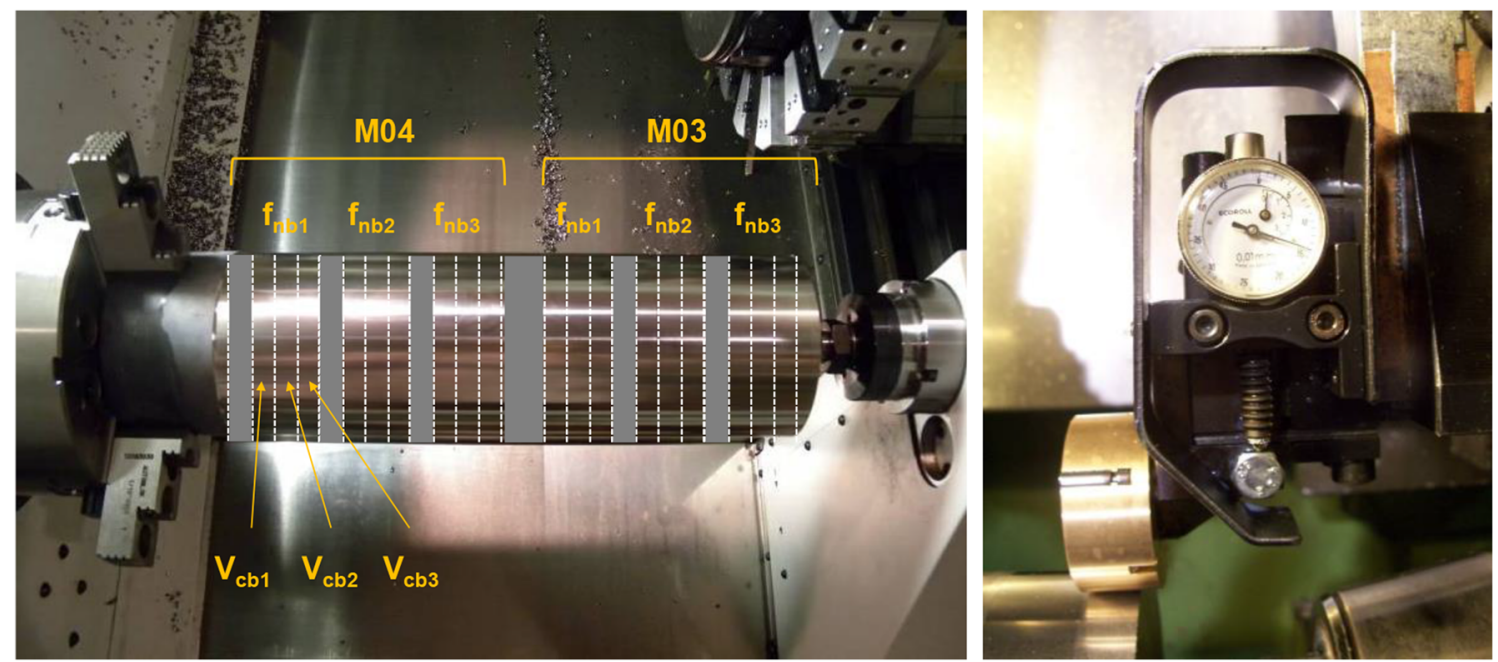

Fig. 6 Experimental set-up. (Left) testing part and burnishing parameters, values are those of burnishing tests. (Right) roller burnishing tool

between the values of the $\mathrm{Y}$ axis just before and after burnishing.

Figure 3 shows the effect of burnishing pressure on workpiece surface profile. Thus, the roughness profiles obtained with the finite element model show that by applying a force of $250 \mathrm{~N}$, the burnishing tool flattens the surface roughness peaks by half. In the figure, roughness peaks appear $0.4 \mathrm{~mm}$ separated, which corresponds to the previous turning feed rate.

By increasing force to $500 \mathrm{~N}$, the midline of the profile decreases, and although some peaks are appreciated at $0.4 \mathrm{~mm}$, burnishing feed marks begins to be noted, generating peaks of roughness at $0.2 \mathrm{~mm}$ (i.e., the burnishing feed). Surface profiles obtained at $750 \mathrm{~N}$ and $1000 \mathrm{~N}$ show that final roughness was generated by the rolling tool, being the peaks at a distance of $0.2 \mathrm{~mm}$. In addition, the roughness midline is very small compared with the initial one, but with these forces, the tolerances of the workpiece are not ensured. It can be concluded that the optimum burnishing force in would be around $500 \mathrm{~N}$, since higher pressures do not guarantee workpiece tolerance and also leads to a waste of energy.

Figure 4 shows the effect of burnishing feed on workpiece surface profile. Roughness profiles obtained by FEM simulations show that final roughness improves at the smallest burnishing feed values. Also, it can be appreciated that the roughness peaks occur at the same distance as the value of burnishing feed in all the simulated cases. The best surface roughness is achieved by applying a burnishing feed of $0.1 \mathrm{~mm} / \mathrm{rev}$; roughness peaks are negligible in comparison with other feed values.

\subsection{Residual stress distributions}

Residual stress distribution based on burnishing feed per revolution is studied here. From an industrial point of view, it is interesting to reduce surface treatment process time by increasing the radial burnishing feed. To investigate residual
Table $2 R a$ and $R z$ roughness results obtained experimentally (average value of three tests)

\begin{tabular}{|c|c|c|c|c|c|c|c|}
\hline & & & & M03 & & M04 & \\
\hline & $F_{\mathrm{b}}[\mathrm{N}]$ & $V_{\mathrm{c}}$ or $V_{\mathrm{cb}}[\mathrm{m} / \mathrm{min}]$ & $f$ or & $R a$ & $R z$ & $R a$ & $R z$ \\
\hline & & & $f_{\mathrm{nb}}[\mathrm{mm} / \mathrm{rev}]$ & & & & \\
\hline Turning & - & 80 & 0.4 & 2.12 & 11.5 & 2.12 & 11.5 \\
\hline Burnishing & 1000 & 80 & 0.4 & 1.16 & 7.19 & 0.92 & 7.34 \\
\hline & & 100 & 0.4 & 1.21 & 9.97 & 1.02 & 7.44 \\
\hline & & 120 & 0.4 & 1.02 & 6.09 & 1.17 & 9.47 \\
\hline & & 80 & 0.2 & 0.94 & 6.74 & 0.94 & 7.7 \\
\hline & & 100 & 0.2 & 1.21 & 9.67 & 1.02 & 7.84 \\
\hline & & 120 & 0.2 & 1.07 & 10.5 & 0.79 & 6.15 \\
\hline & & 80 & 0.1 & 0.90 & 7.01 & 0.74 & 5.87 \\
\hline & & 100 & 0.1 & 0.82 & 4.99 & 0.79 & 6.58 \\
\hline & & 120 & 0.1 & 0.83 & 5.02 & 0.79 & 6.42 \\
\hline
\end{tabular}


Fig. 7 3D topography after turning operation

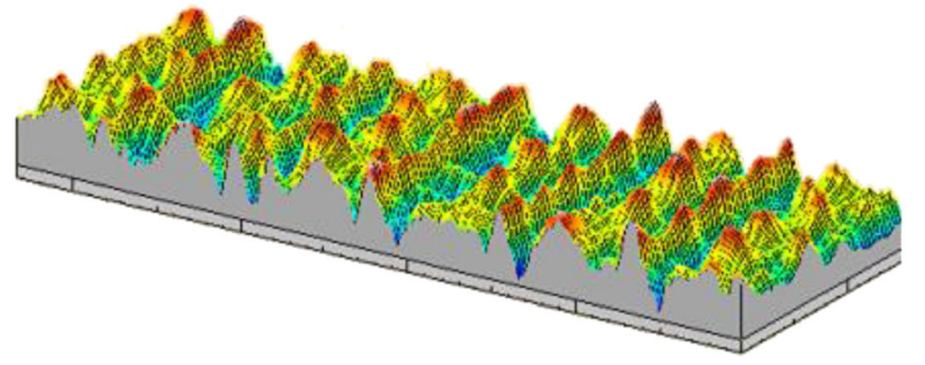

$\mu \mathrm{m}$

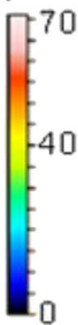

stresses in two directions, (a) along the material surface and (b) the in-depth direction when using different radial feeds and burnishing pressures, a 2D numerical simulation is performed.

Figure 5 shows the effect of burnishing feed on simulated residual stress distribution. Thus, the higher the burnishing feed is, the higher the compressive stresses are generated. In fact, burnishing speed variation hardly affects workpiece surface finish and hardness. Thus, it is possible to burnish using the maximum rotational speed supported by the lathe, reducing processing time in this way. Otherwise, burnishing feed per revolution is important for increasing productivity. Total process time analysis includes optimum turning feed (initial roughness) and burnishing feed.

\section{Experimental set-up}

Some tests must be performed to check the feasibility of these numerical approaches. Thus, some cutting experiments were conducted in a CMZ TC25BTY turning center with a FANUC® $31 \mathrm{iT}$ HVi numeric control, 25-Kw maximum speed $3000 \mathrm{rpm}$. The workpiece, a cylinder of ADI 1000, was rigidly clamped and machined using typical cutting conditions for roughing operations. The turning tool was a carbide one type CNMG12, without chipbreaker; new inserts were used in each test. ADI correct grade was tested by cuttingoff several coupons. After machining, burnishing tests were carried out. An Ecorrol ${ }^{\circledR}$ EG5-1 burnishing tool was used; values used in tests are shown in Table 1. This tool is based on a spring preloaded provided with a dial to control the rolling force, with a relation of $K 4.1 \mathrm{E} 6 \mathrm{~N} / \mathrm{m}$. Tool rollers are made out of sintered carbide.

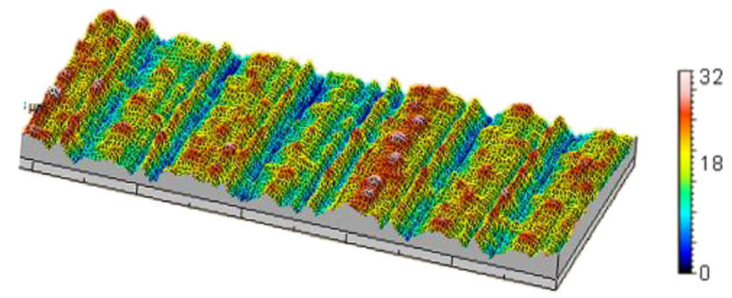

Testpiece surface was prepared by turning, using common values in roughness operations for this material; cutting speed was $80 \mathrm{~m} / \mathrm{min}$. After turning, rolling was performed using different parameters. The force applied was the maximum acceptable for this roller tool, $1000 \mathrm{~N}$. The idea was to generate a great deformation on the surface, eliminating the previous turning pattern. Burnishing feed was checked in three levels, and burnishing direction was applied both in the turning direction and helix-crossed direction (Fig. 6).

\section{Results and discussion}

Table 2 shows roughness obtained in burnishing tests, burnishing along the same rotation direction than in the previous turning (M03, turning and rolling are parallel spirals), and also when the rotation direction was just the opposite (M04, so in this case the pattern was helix-crossed; turning and rolling spirals are in opposite directions). The purpose was to check whether using the latter, the helix crossing approach, the elimination of directionality patterns generated by the previous turning is possible. Values in the table are average values of three tests, with divergence of 5\% maximum.

Results show that roughness parameters are better using helix-crossed burnishing. In all the cases, the final roughness is better with small values of feed per revolution. Regarding the cutting speed variation, results do not make clear the influence of this parameter on the surface quality obtained.

Figure 7 shows a 3D surface topography of the turned surface after roughing conditions. Typical turning peaks and valleys (and grooves) are shown in this picture. On the other hand, in Fig. 8 (left), the topography after burnishing in M03 is shown (turning was also in M03). A decrease in surface

Fig. 8 (Left) 3D topography after conventional burnishing M03, same turning rotational direction. (Right) 3D topography after burnishing M04 (helixcrossed), directional pattern elimination is appreciated 
Table 3 Obtained results from roller and ball burnishing processes

\begin{tabular}{|c|c|c|c|c|c|c|c|}
\hline & \multirow[b]{2}{*}{ Parameters } & \multicolumn{3}{|c|}{ Roller burnishing } & \multicolumn{3}{|c|}{ Ball burnishing } \\
\hline & & $\begin{array}{l}R a \\
\quad[\mu- \\
\quad \mathrm{m}]\end{array}$ & $\begin{array}{l}R z \\
\quad[\mu- \\
\mathrm{m}]\end{array}$ & $\begin{array}{r}\text { Hardness } \\
{[\mathrm{HBN}]}\end{array}$ & $\begin{array}{l}R a \\
\quad[\mu- \\
\mathrm{m}]\end{array}$ & $\begin{array}{l}R z \\
\quad[\mu- \\
\mathrm{m}]\end{array}$ & $\begin{array}{r}\text { Hardness } \\
{[\mathrm{HBN}]}\end{array}$ \\
\hline Turning & $\begin{array}{c}V_{c}=200 \mathrm{~m} / \mathrm{min} \\
f_{n}=0.4 \mathrm{~mm} / \mathrm{rev}\end{array}$ & 3.66 & 15.3 & 153 & 3.56 & 14.2 & 151 \\
\hline Burnishing & $\begin{aligned} V_{b} & =150 \mathrm{~m} / \mathrm{min} \\
F_{b} & \approx 550 \mathrm{~N} \\
f_{n b} & =0.2 \mathrm{~mm} / \mathrm{rev}\end{aligned}$ & 0.105 & 1.08 & 238 & 0.31 & 1.72 & 242 \\
\hline
\end{tabular}

roughness is observed, but the turning characteristic roughness pattern is still there, parallel grooves-like.

However, Fig. 8 (right) is with turning in M03 and burnishing in M04, it shows that the well-known turning pattern was disappeared, obtaining an isotropic surface finishing after helix-crossed burnishing application. Finishing is near to be isotropic.

\section{Roller burnishing vs ball burnishing}

After results using roller tools in the previous section, a comparison using mechanical roller-burnishing technique and hydrostatic ball-burnishing technique is presented. To make the comparison, ball-burnishing and roller-burnishing tests were performed using the same process parameters and on the same material. The burnishing force used in the tests was $550 \mathrm{~N}$ (0.15 $\mathrm{mm}$ dial), similar to the force measured when using the hydrostatic equipment at $20-\mathrm{MPa}$ pressure. Turning and burnishing parameters and obtained roughness results are shown in Table 3.

Values are the average of three tests.

The results show that the final surface roughness was better when using a single roller mechanical burnisher than using a ball burnisher. For the same feed per revolution and radius of the roller or ball, a diagram of the expected theoretical profile

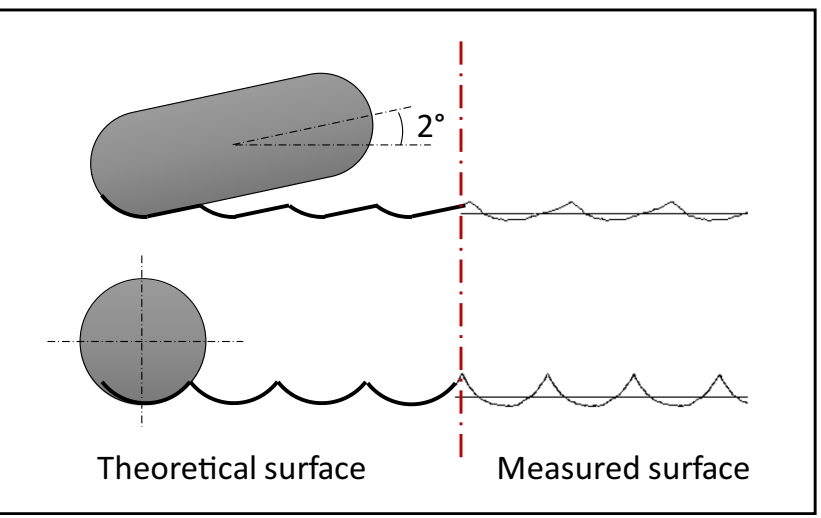

Fig. 9 Finishing geometry sketch using roller and ball burnishing process (left) and the comparison with real measured values (right) and the actual surface obtained using both tools are shown in Fig. 9.

Roughness values using roller burnishing is always lower than using a ball one. Rollers normally work at a position angle of approximately $2^{\circ}$; therefore, the lateral roller straight area crushes the roughness peaks as it passes by, thus achieving a better finish. So, final finishing depends on the roller rounded edge geometry and the nominal angle of inclination at which it works. This fact, on the other hand, means that roller tools can only be used in simple geometries. For complex geometries and freeform surfaces, the most suitable tool is the ball burnishing tool, as presented in $[12,13]$ by authors.

With regard to residual stresses, X-ray diffraction measurements for both techniques are shown in Fig. 10. Results showed small quantitative differences, especially on the part surface where the compressive stresses generated by the roller are lower than those generated by the ball $(\approx 150 \mathrm{MPa}$ lower). However, the stress field is very similar along depth, marking practically equal values under $0.1 \mathrm{~mm}$ of treated surfaces.

\section{Conclusions}

The influence of roller burnishing on ADI 1000 turned parts was investigated. A numerical approach analyzed the influence of the primary process parameters. In addition, surface

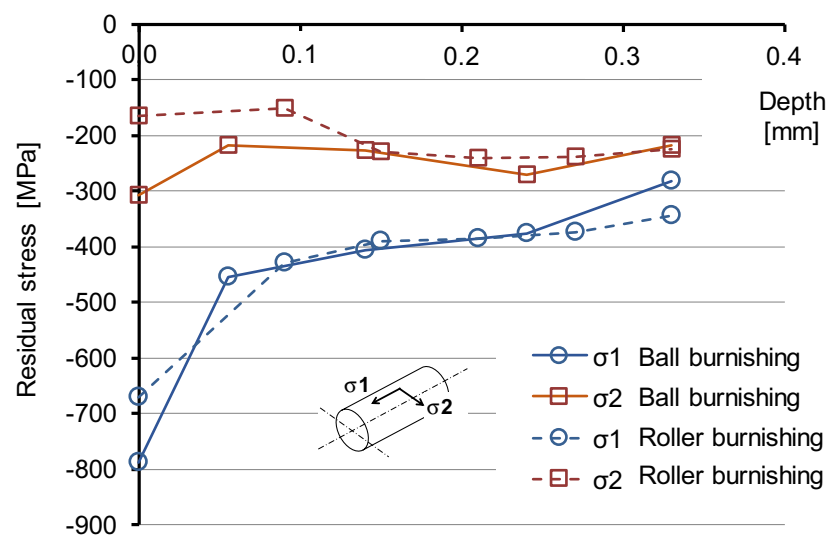

Fig. 10 Residual stresses comparison generated after ball burnishing and after roller burnishing application 
characteristics achieved were analyzed. And finally, a comparison between two different tool geometries, roller and ball, is also presented. Based on the experimental results, the following conclusions can be pointed out:

- Roller burnishing process improves significantly the surface roughness of ADI 1000 parts.

- Combining the helix-crossed rolling approach and low values of feed per revolution, surface roughness improvement could be achieved.

- Directional roughness patterns generated in turning operations could be eliminated if rolling is applied in an opposite rotational direction (M03 and M04). The idea has direct application in hard turning, in which the kinematically defined pattern is always a drawback in comparison with grinding.

Roller burnishing improves both physical and mechanical properties of ADI 1000 turned parts. Particularly, this technique improves surface quality (even reaching $0.7 \mu \mathrm{m} \mathrm{Ra}$ ) and introduces compressive residual stresses, which are favorable for increasing the piece fatigue life and for improving the wear resistance.

Burnishing can be performed using the maximum spindle speed and feed rate of lathes. This fact, along with the advantage of applying burnishing on the same machine tool that produced the finishing operation, makes burnishing a fast and simply finishing technique, significantly reducing production time compared with grinding or hand polishing.

Acknowledgments The authors are grateful to the Spanish ministry Project DPI2016-74845-R and to the Basque government Project ELKARTEK Procoda. The authors are also grateful to the Basque government group IT IT1337-19. Thanks are addressed to all people staying patiently at home in this virus crisis and to medicine people taking care of other people and fighting COVID 19.

\section{References}

1. Rodríguez A, López de Lacalle LN, Celaya A, Lamikiz A, Albizuri J (2012) Surface improvement of shafts by the deep ball-burnishing technique. Surf Coat Technol 206:2817-2824

2. Rodríguez A, López de Lacalle LN, Fernández A, Braun S (2014) Elimination of surface spiral pattern on brake discs. Journal of Zhejiang University-SCIENCE A (Applied Physics \& Engineering) 15(1):53-60

3. Keough J, Hayrynen K, Pioszak G (2010) Designing with austempered ductile iron (ADI). AFS Proc 1-15

4. Sahin Y, Kilicli V, Ozer M, Erdogan M Comparison of, abrasive wear behavior of ductile iron with different dual matrix structures. Wear 268:153-165. https://doi.org/10.1016/j.wear.(2010)0.07.008

5. Cakir M, Isik Y (2008) Investigating the machinability of austempered ductile irons having different austempering temperatures and times. Materials \& Design, Vol 29(5):937-942

6. Klocke F, Arft M, Lung D (2010) Material-related aspects of the machinability of austempered ductile iron. Prod Eng 4(5):433-441
7. López de Lacalle LN, Fernández Valdivielso A, Amigo FJ, Sastoque L (2020) Milling with ceramic inserts of austempered ductile iron (ADI): process conditions and performance. Int J Adv Manuf Technol, Under review

8. de Sousa JAG, Sales WF, Machado AR (2018) A review on the machining of cast irons. Int J Adv Manuf Technol 94:4073-4092

9. S. Wojciechowski, R. Talar, P. Zawadzki, M. Wieczorowski, (2020) Evaluation of physical indicators and tool wear during grooving of spheroidal cast iron with a novel $\mathrm{WCCo} / \mathrm{cBN}$ (BNDCC) inserts, Wear, Volumes 454-455, 203301

10. Budic I, Vitez I, Marusic V (2007). Residual stresses in iron castings, Chapter 49 in DAAAM International Scientific Book 2007, B. Katalinic (Ed.), Published by DAAAM International, ISBN 3 901509-60-7, ISSN 1726-9687, Vienna, Austria

11. Saldaña-Robles A, Plascencia-Mora H, Aguilera-Gómez E, Saldaña-Robles A, Marquez-Herrera A, De la Peña JAD (2018) Influence of ball-burnishing on roughness, hardness and corrosion resistance of AISI 1045 steel. Surf Coat Technol 339:191-198

12. Luca L, Neagu-Ventzel S, Marinescu I (2005) Effects of working parameters on surface finish in ball-burnishing of hardened steels. Precis Eng 29:253-256

13. Świrad S, Wydrzynski D, Nieslony P, Krolczyk GM (2019) Influence of hydrostatic burnishing strategy on the surface topography of martensitic steel. Measurement 138:590-601

14. Rodríguez A, López de Lacalle LN, Celaya A, Fernández A, Lamikiz A (2011) Ball burnishing application for finishing sculptured surfaces in multi-axis machines. Int $\mathrm{J}$ of Mechatron and Manuf Syst 4(3-4):220-237

15. López de Lacalle LN, Rodriguez A, Lamikiz A, Celaya A, Alberdi R (2011) Five-axis machining and burnishing of complex parts for the improvement of surface roughness. Mater Manuf Process 26(08):997-1003

16. Golden PJ, Shepard MJ (2007) Life prediction of fretting fatigue with advanced surface treatments. Mat Sci Eng 468-470:15-22

17. Prevéy P, Cammett J (2004) The influence of surface enhancement by low plasticity burnishing on the corrosion fatigue performance of AA7075-T6. Int J of Fatigue 26/9:975-982

18. Sánchez Egeaa AJ, Rodríguez A, Celentano D, Calleja A, López de Lacalle LN (2019) Joining metrics enhancement when combining FSW and ball-burnishing in a 2050 aluminium alloy. Surface \& Coatings Technology 367:327-335

19. Rodríguez A, Calleja A, López de Lacalle LN, Pereira O, González H, Urbikain G, Laye J (2019) Burnishing of FSW aluminum Alcu-li components. Metals MDPI 9(2):260. https://doi.org/10.3390/ met 9020260

20. Gil A, Rodríguez A, Penalva M, Ortiz M, López de Lacalle LN, Iriondo E (2018) Improvement of the surface quality of incrementally formed parts by means of hydrostatic ball burnishing. DYNA 93(6):650-655

21. Shiou FJ, Hsu CC (2008) Surface finishing of hardened and tempered stainless tool steel using sequential ball grinding, ball burnishing and ball polishing processes on a machining Centre. J Mater Process Tech Vol 205(1-3):249-258

22. Fattouh M, El-Khabeery MM (1989) Residual stress distribution in burnishing solution treated and aged 7075 aluminum alloy. Int J Mach Tool Manu 29:153-160

23. Avilés R, Albizuri J, Rodríguez A, López de Lacalle LN (2013) Influence of low-plasticity ball burnishing on the high-cycle fatigue strength of medium carbon AISI 1045 steel. Int J Fatigue 55:230 244

24. Avilés A, Avilés R, Albizuri J, Pallarés-Santasmartas L, Rodríguez A (2019) Effect of shot-peening and low-plasticity burnishing on the high-cycle fatigue strength of DIN 34CrNiMo6 alloy steel. Int J Fatigue 119:338-354 
25. Kawagoishi N, Nagano T, Moriyama M, Kondo E (2009) Improvement of fatigue strength of maraging steel by shot peening. Mater Manuf Process Vol 24(12):1431-1435

26. Hassan AM, Al-Jalil HF, Ebied AA (1998) Burnishing force and number of ball passes for the optimum surface finish of brass components. J Mater Process Technol 83:179-179

27. El-Axir MH, Othman OM, Abodiena AM (2008) Study on inner surface finishing of aluminium alloy 2014 by ball burnishing process. J Mater Process Technol 202:435-442

28. Bouzid W, Tsoumarev O, Saï K (2004) An investigation of surface roughness of burnished AISI 1042 steel. Int J Adv Manuf Technol 24:120-125

29. Rötter K. (2002) Walzen hartgedrehter Oberflaechen, Ph. D. Dissertation, WZL, RWTH, Technical University of Aachen, Germany

30. Sartkulvanich P, Sitan T, Jasso F, Rodriguez C (2007) Finite element modelling of hard roller burnishing: an analysis on the effects of process parameters upon surface finish and residual stresses. J Manuf Sci Eng 129:705-716

31. Tajane RS, Pawar PJ (2020) Investigation into burnishing to minimize heat treatment in drill manufacturing. Mater Manuf Process 35:817-825. https://doi.org/10.1080/10426914.2020.1743848
32. Travieso-Rodríguez JA, Dessein G, González-Rojas HA (2011) Improving the surface finish of concave and convex surfaces using a ball burnishing process. Mater Manuf Process 26(12):1494-1502

33. Talon AG, Lopes JC, Tavares AB, Sato BK, Rodrigues AR, Genovez MC, Dinis Pinto TA, de Mello HJ, Aguiar PR, Bianchi EC (2019) Effect of hardened steel grinding using aluminum oxide wheel under application of cutting fluid with corrosion inhibitors. Int J Adv Manuf Technol 104:1437-1448

34. de Moraes DL, Garcia MV, Lopes JC, Ribeiro FSF, de Angelo Sanchez LE, Foschini CR, de Mello HJ, Aguiar PR, Bianchi EC (2019) Performance of SAE 52100 steel grinding using MQL technique with pure and diluted oil. Int J Adv Manuf Technol 105: 4211-4223

35. Lopes JC, Garcia MV, Volpato RS, de Mello HJ, Ribeiro FSF, de Angelo Sanchez LE, de Oliveira Rocha K, Neto LD, Aguiar PR, Bianchi EC (2020) Application of MQL technique using TiO2 nanoparticles compared to MQL simultaneous to the grinding wheel cleaning jet. Int J Adv Manuf Technol 106:2205-2218

Publisher's note Springer Nature remains neutral with regard to jurisdictional claims in published maps and institutional affiliations. 